\title{
Asymmetry dynamics in real exchange rates: new results on East Asian currencies
}

\begin{abstract}
This paper provides new evidence on the purchasing power parity (PPP) hypothesis in six East Asian countries. Based on nonlinear unit root tests, we discovered that the results are broadly consistent with the fact that real exchange rates (RERs) follow a nonlinear mean reversion process. We presented new evidence that the adjustment towards the PPP parity is asymmetric (LSTAR process) above and below the equilibrium value in all but one case the Malaysian ringgit (MYR). The empirical results suggest that it is important that the conventional tests of PPP be amended to take account of asymmetries in the adjustment process in RERs.
\end{abstract}

Keyword: Real exchange rate; STAR; Nonlinear; Mean reversion; East Asian 